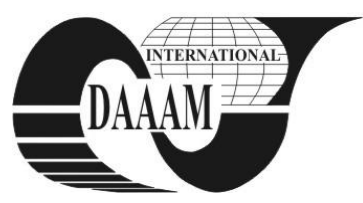

Annals of DAAAM for 2011 \& Proceedings of the 22nd International DAAAM Symposium, Volume 22, No. 1, ISSN 1726-9679 ISBN 978-3-901509-83-4, Editor B. Katalinic, Published by DAAAM International, Vienna, Austria, EU, 2011 Make Harmony between Technology and Nature, and Your Mind will Fly Free as a Bird Annals \& Proceedings of DAAAM International 2011

\title{
INDUCTIVE ROTARY PROBE FOR PARTIAL DISCHARGE DIAGNOSTICS
}

\author{
PIHERA, J[osef]; MENTLIK, V[aclav] \& TRNKA, P[avel]
}

\begin{abstract}
When the partial discharge within insulation system of generator stator occurs, there are several methods to detect the signal of such dangerous discharge. First the global method detecting discharge current impulse and second the method based on detecting of discharge emitted electro-magnetic energy. The indirect measuring of current discharge using inductive probe is described in this paper. This method uses inductive probe which output is analyzed by digital measuring oscilloscope technique and software specially developed to partial discharge detailed analysis.

Instead of common global test there is necessary to use special localization method, as described above, for analyzing the ratio of partial discharge activity within particular stator slot of electrical rotating generator and its stator slots respectively.

Method of inductive probe in differential setup is very useful to this diagnostics of rotating machines

Key words: partial discharge, diagnostics, probe, generator
\end{abstract}

\section{INTRODUCTION}

Localization methods of partial discharges are useful for detailed survey of generator condition diagnostics during it's technical life. The localization method is thus necessary to implement into common global partial discharge testing methods.

There exist several localization methods developed within last year's which are used to detect partial discharges in slot of generators. These on-line methods of partial discharge detection are based on antenna type coupler (slot coupler) (Hudon, Sedding, Maughan). The disadvantage of slot coupler is in necessity of built-up of coupler into the slot during winding application. This brings the problems during insulation system design and winding application technology and of course another part, of serial-parallel reliability model of whole generator, which could be damaged and consequently break whole engine.

The method of rotating inductive probe is based on off-line measurement of partial discharges and brings very detailed information about conditions from partial discharge point of view of particular slot of electric generator and its stator respectively.

This probe is connected with device of precise rotation movement control. The mechanism of measurement is described as indirect electrical method of partial discharge diagnostics and is useful for localization of damaged bar or slot and its insulation system respectively within stator winding of generators.

Basic principle of this method is based on inductive probe with ferrite core of "C" shape (Mentlík). The dimensions of core are equal to dimensions of slot width because when the core of probe is directly above the slot the magnetic circuit of current transformer is built. There are pulses in the secondary winding of this current transformer which corresponds to the partial discharge activity of particular slot (Fig.1).
The method is based on these of two current transformers (each on one side of stator of generator) which are in differential mode of connection. This setup eliminates disturbances from ambient sources and amplifies the partial discharge pulses within the stator, particular slot respectively.

Each slot of generator is investigated as the probe rotates in the stator. The results are in the comparative method of diagnostics because the probe output is in $\mathrm{mV}$ scales. Therefore there is not necessary (even impossible) the calibration of apparent charge $\mathrm{q}(\mathrm{pC})$

Device is programmed for two modes of motions and analyses. First, the continuous rotation movement of one rotation with constant speed. There are investigated all slots during one rotation at this mode. The output is given as table or 2D graph where $\mathrm{x}$-axis represents slot number and $\mathrm{y}$-axis represents probe output in $\mathrm{mV}$ which is equal to partial discharge activity in given slot (Fig. 4).

The condition of winding is evaluated as relation between actual average values of all slots and of particular measured slot. The slots which have partial discharge activity higher then $20 \mathrm{~dB}$ are necessary to be more investigated and repaired consequently.

The second mode of analysis is then the possibility of stopping the probe at each slot for given time. At this mode the partial discharge phase characteristics can be measured and analyzed. The output of this measurement is histogram or phase resolved characteristics of partial discharge of given slot.

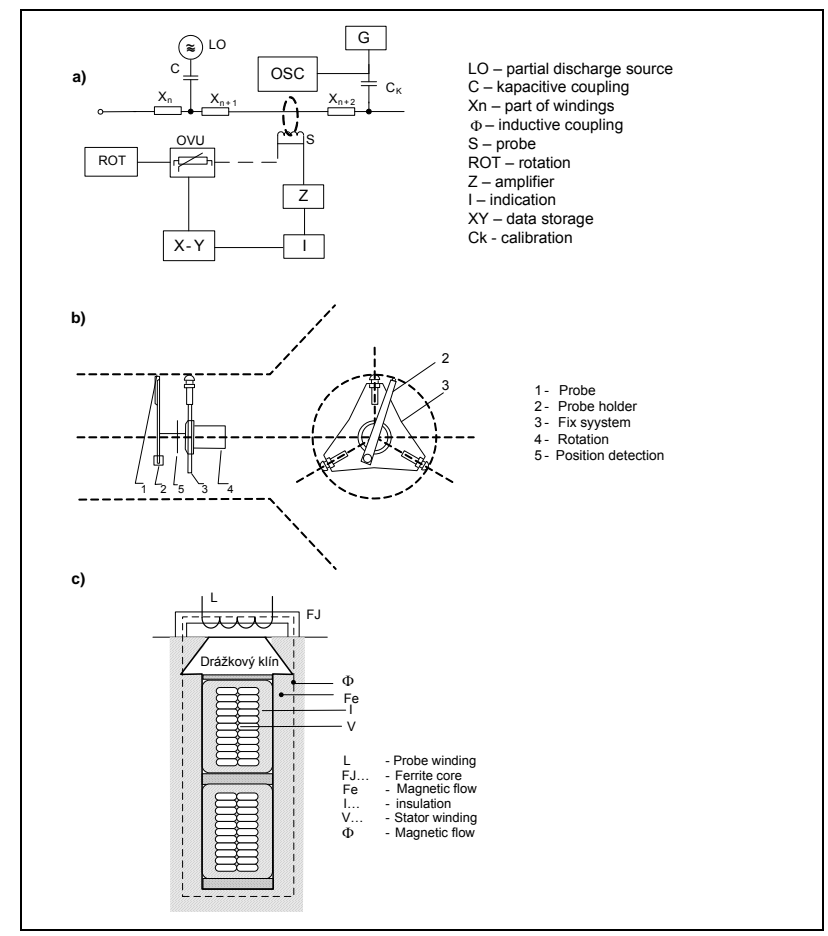

Fig. 1. Probe scheme 


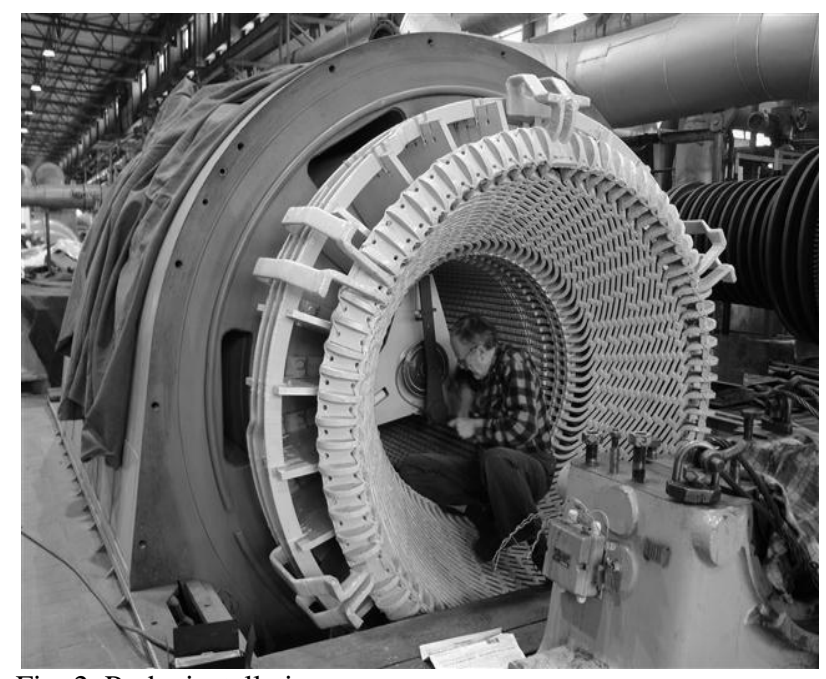

Fig. 2. Probe installation

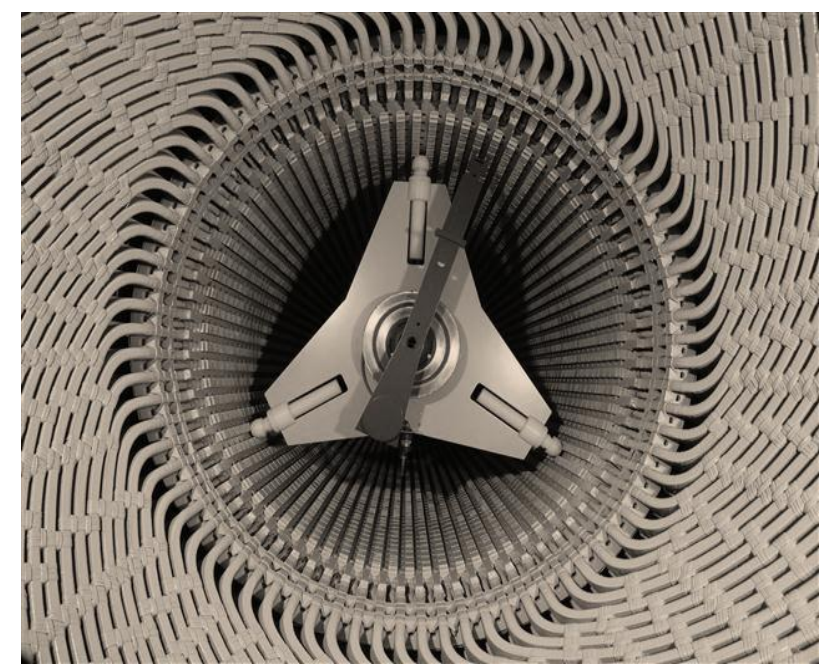

Fig. 3. Probe installed inside generator stator

\section{MEASURING PROCEDURE}

The measurement is applicable as off-line method on generator stator where the rotor is not present. It is applicable on whole generator winding or separately for each phase of winding. Test voltage is connected from one side, the other side not connected with ground.

The rotating probes are mounted to both sides of stator and centered for rotating movement of probe without any problems with $1 \mathrm{~mm}$ distance from slot (Fig. 3 and Fig. 4).

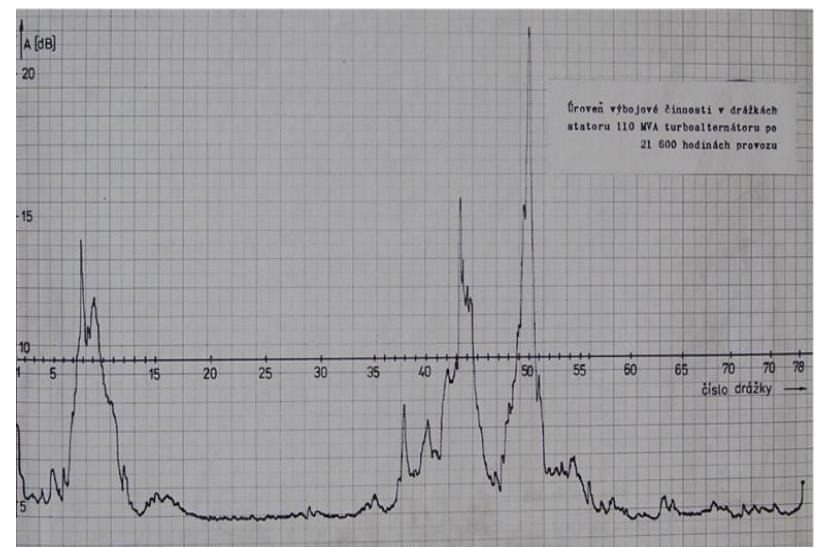

Fig. 4. Probe output

\section{CRITERIA}

Median is used for classification of insulation system properties from partial discharge point of view wit rotating probe using. There is evaluated the deviation of particular slot from median $\mathbf{x}_{\mathbf{m} e d}$ which represents the statistical centre value of measured $\mathbf{x}_{\mathbf{i}}$ values of particular slots. When the number of $\mathbf{x}_{\mathbf{i}}$ is odd the median is clear, when the $\mathbf{x}_{\mathbf{i}}$ number is even then median is average of two values as given by equation 1 .

$$
\mathrm{P}(\mathrm{X} \leq \mathrm{Me}) \geq 0,5 \text { a zároveň } \mathrm{P}(\mathrm{X} \geq \mathrm{Me}) \geq 0,5
$$

The criteria for evaluation of insulation properties is used the ratio of intensity of partial discharges xi (for example measured voltage $u_{i}$ or apparent charge $q_{i}$ ) of investigated slot and median of this values $\mathrm{x}_{\text {med }}$ of all slots of generator (2).

$$
\text { bottom level }<\frac{\mathrm{x}_{\mathrm{i}}}{\mathrm{x}_{\mathrm{med}}}<\text { upper level }
$$

\section{CONCLUSIONS}

The device for partial discharge measurement and detailed analysis of the stator winding partial discharge behavior bring to the technical diagnostics of rotating machines modern and enhanced view to the evaluation of measured data and estimation of lifetime. The precision localization of partial discharge source within generator winding and the localization of damaged bars is very important for generator lifetime estimation and for repair planning.

Described method of partial discharge localization and identification using inductive rotating probe is very powerful tool for service and maintenance of electrical rotating machines and bring saves and safeness for generator owners.

\section{ACKNOWLEDGEMENTS}

This research was funded by the Ministry of Education, Youth and Sports of the Czech Republic, MSM 4977751310

Diagnostics of Interactive Processes in Electrical Engineering. The authors are grateful for the support of this program.

\section{REFERENCES}

Hudon, C.; Torres, W.; Belec, M.; Contreras, R.; , Comparison of discharges measured from a generator's terminals and from an antenna in front of the slots, Electrical Insulation Conference and Electrical Manufacturing \& Coil Winding Conference, 2001., pp.533-536, 2001

Maughan, C.V.; , Turbine-generator condition assessment using Electromagnetic Interference (EMI) testing, Electrical Insulation (ISEI), Conference Record of the 2010 IEEE International Symposium on., pp.1-5, 6-9 June 2010

H.G. Sedding, S.R. Campbell, G.C. Stone, G.S. Klempner, A New Sensor for Detecting Partial Discharges in Operating Turbine Generators, IEEE Trans. EC, December 1991,

Mentlík. V. Device for rotating probe control, CZ Pattent No. 1981-6619

Mentlík. V Setup for partial discharge diagnostics within dielectric system of rotating machines, CZ Patent No. 1981-6620

Matsumoto, S.; Three-axis loop antenna for the detection of partial discharge signal, Electrical Insulating Materials, 2008. (ISEIM 2008). pp.28-31, 7-11 Sept. 2008 